\title{
Mechanism of DNA resection during intrachromosomal recombination and immunoglobulin class switching
}

\author{
Anne Bothmer, ${ }^{1}$ Philipp C. Rommel, ${ }^{1}$ Anna Gazumyan, ${ }^{1,2}$ Federica Polato, ${ }^{3}$ \\ Colleen R. Reczek, ${ }^{4}$ Matthias F. Muellenbeck, ${ }^{1}$ Sonja Schaetzlein, ${ }^{5}$ \\ Winfried Edelmann, ${ }^{5}$ Phang-Lang Chen, ${ }^{6}$ Robert M. Brosh Jr., ${ }^{7}$ \\ Rafael Casellas, ${ }^{8}$ Thomas Ludwig, ${ }^{4}$ Richard Baer, ${ }^{4}$ André Nussenzweig, ${ }^{3}$ \\ Michel C. Nussenzweig, ${ }^{1,2}$ and Davide F. Robbiani ${ }^{1}$
}

\footnotetext{
'Laboratory of Molecular Immunology and ${ }^{2}$ Howard Hughes Medical Institute, The Rockefeller University, New York, NY 10065 ${ }^{3}$ Laboratory of Genome Integrity, National Cancer Institute, National Institutes of Health, Bethesda, MD 20892 ${ }^{4}$ Institute for Cancer Genetics, Columbia University Medical Center, New York, NY 10032

${ }^{5}$ Departments of Cell Biology and Genetics, Albert Einstein College of Medicine, Bronx, NY 10461 ${ }^{6}$ Department of Biological Chemistry, University of California-Irvine, Irvine, CA 92697 ${ }^{7}$ Laboratory of Molecular Gerontology, National Institute on Aging, National Institutes of Health, Baltimore, MD 21224 ${ }^{8}$ Genomics and Immunity, NIAMS, National Cancer Institute, National Institutes of Health, Bethesda, MD 20892
}

\begin{abstract}
DNA double-strand breaks (DSBs) are byproducts of normal cellular metabolism and obligate intermediates in antigen receptor diversification reactions. These lesions are potentially dangerous because they can lead to deletion of genetic material or chromosome translocation. The chromatin-binding protein 53BP1 and the histone variant H2AX are required for efficient class switch (CSR) and V(D)J recombination in part because they protect DNA ends from resection and thereby favor nonhomologous end joining (NHEJ). Here, we examine the mechanism of DNA end resection in primary B cells. We find that resection depends on both CtBP-interacting protein (CtIP, Rbbp8) and exonuclease 1 (Exo1). Inhibition of CtIP partially rescues the CSR defect in 53BP1- and H2AX-deficient lymphocytes, as does interference with the RecQ helicases Bloom (BIm) and Werner (Wrn). We conclude that CtIP, Exo1, and RecQ helicases contribute to the metabolism of DNA ends during DSB repair in B lymphocytes and that minimizing resection favors efficient CSR.
\end{abstract}

\section{CORRESPONDENCE}

D.F. Robbiani:

drobbiani@rockefeller.edu

Abbreviations used: AID, activation-induced cytidine deaminase; A-NHEJ, alternative nonhomologous end joining; ATM, ataxia-telangiectasia mutated; C-NHEJ, classical NHEJ; CSR, class switch recombination; CtIP, CtBPinteracting protein; DSB, DNA double-strand break; ssDNA, single-stranded DNA.
DNA double-strand breaks (DSBs) can be repaired locally or recombined to produce chromosome rearrangements. These events are common to lymphomas, leukemias, and sarcomas, and can also be found in prostate, lung, and other solid cancers (Futreal et al., 2004; Mitelman et al., 2007; Nussenzweig and Nussenzweig, 2010; Robbiani and Nussenzweig, 2012). The mechanisms that govern chromosomal rearrangements

A. Bothmer and P.C. Rommel contributed equally to this paper.

A. Bothmer's present address is the Cancer Genetics Program, Beth Israel Deaconess Medical Center, Harvard Medical School, Boston, MA 02215 .

M.F. Muellenbeck's present address is the Molecular Immunology Group, Max Planck Institute for Infection Biology, 10117 Berlin, Germany.

T. Ludwig's present address is the Dept. of Molecular and Cellular Biochemistry, Ohio State University Wexner

Medical Center, Columbus, OH 43210. are only partially understood, but paired DSBs are sufficient to initiate translocation, whereas chromosome deletion can result from joining of two paired intrachromosomal DSBs or from resection of a single break. A shared feature of these reactions is the loss of genetic information, ranging from a few nucleotides to several megabases (Robbiani et al., 2008; Bothmer et al., 2010, 2011).

Lymphocytes are particularly prone to transformation by chromosome rearrangements, in part because they undergo programmed DNA damage during $I g$ and $T C R$ gene diversification reactions (Nussenzweig and Nussenzweig, 2010;

2013 Bothmer et al. This article is distributed under the terms of an AttributionNoncommercial-Share Alike-No Mirror Sites license for the first six months after the publication date (see http://www.rupress.org/terms). After six months it is available under a Creative Commons License (Attribution-Noncommercial-Share Alike 3.0 Unported license, as described at http://creativecommons.org/licenses/ by-nc-sa/3.0/) 
Gostissa et al., 2011). In mature B cells, DSBs are requisite intermediates in class switch recombination (CSR), which is a deletional recombination reaction that alters the effector function of antibody molecules. During CSR, the enzyme activation-induced cytidine deaminase (AID) converts cytosines into uracils at switch regions on the Ig heavy chain gene $(I g h)$. Excision of uracils from both DNA strands leads to staggered DNA breaks at donor and acceptor switch regions. These lesions are normally detected as DSBs by the Mre11Rad50-NBS1 (MRN) complex, which initiates a cascade of events that leads to phosphorylation of H2AX, recruitment of 53BP1, and, eventually, end joining by classical or alternative nonhomologous end-joining pathways (C- or ANHEJ; Petersen et al., 2001; Reina-San-Martin et al., 2004; Neuberger et al., 2005; O’Driscoll and Jeggo, 2006; Stavnezer et al., 2008; Noon and Goodarzi, 2011; Gostissa et al., 2011). However, Igh breaks can also be aberrantly joined to AIDmediated DSBs in non- $I g$ genes, including oncogenes that are commonly translocated to the $I g$ loci in lymphomas (Robbiani et al., 2008; Chiarle et al., 2011; Klein et al., 2011; Hakim et al., 2012; Zhang et al., 2012).

In addition to their role in initiating the DNA damage response, 53BP1 and $\mathrm{H} 2 \mathrm{AX}$ are essential for CSR (Petersen et al., 2001; Manis et al., 2004; Ward et al., 2004). These proteins are believed to contribute to the switch reaction by facilitating synapsis and by protecting DNA ends from resection. In their absence, broken DNA is resected to produce single-stranded DNA (ssDNA), which serves as a substrate for repair by alternative pathways characterized by increased junctional microhomology (Bothmer et al., 2010; Bunting et al., 2010; Gostissa et al., 2011; Helmink et al., 2011). It has been suggested that alternative repair favors abortive open and shut joining within a switch region (intra-switch recombination) at the expense of productive joining between different switch regions (inter-switch recombination; Bothmer et al., 2010). However, the precise role of resection and the factors that mediate this process during CSR have not been defined.

Genetic studies in yeast and work in human cells have implicated endonucleases, exonucleases, and helicases in DNA resection. Specifically, yeast Sae2 (CtBP-interacting protein [CtIP]) has been implicated together with the MRX (MRN) complex in the initial trimming phase of resection, whereas Exo1 and the RecQ helicase Sgs1 have been shown to promote the subsequent extension of resected tracts (Mimitou and Symington, 2008; Zhu et al., 2008; Symington and Gautier, 2011). Less is known about the effectors of DNA resection in mammalian cells, especially in the context of physiological DNA damage in primary cells. Knockdown of CtIP protects DNA ends from being resected during $\mathrm{V}(\mathrm{D}) \mathrm{J}$ recombination in the absence of H2AX (Helmink et al., 2011), and in lymphocytes undergoing CSR, inhibition of ataxia-telangiectasia mutated (ATM) suppresses the increased end resection that occurs in the absence of 53BP1 (Bothmer et al., 2010). However, ATM is a kinase, not a nuclease, and it acts on a multitude of targets during the DNA damage response (Matsuoka et al., 2007; Bensimon et al., 2010).

Here, we show that both CtIP and Exo1 are in part responsible for the processing of DNA ends during intrachromosomal joining of tandem DSBs. In addition, we show that preventing resection promotes CSR in 53BP1- and H2AXdeficient lymphocytes.

\section{RESULTS}

\section{Resection by CtIP and Exo1}

In the absence of $53 \mathrm{BP} 1$ or $\mathrm{H} 2 \mathrm{AX}$, DNA ends are resected and repaired more frequently via junctional microhomology characteristic of alternative nonhomologous end joining (A-NHEJ), a phenotype that is reverted by ATM inhibition (Bothmer et al., 2010, 2011; Bunting et al., 2010). To identify the enzymes responsible for resection, we analyzed joining products between two I-SceI sites spaced by $96 \mathrm{~kb}$ at the $I g h$ locus on mouse chromosome 12 (Fig. 1 A, IgH ${ }^{\mathrm{I}-96 \mathrm{k}}$; Bothmer et al., 2010). The analysis was performed in AID $^{-/-}$B lymphocytes, to exclude potentially confounding effects of AID breaks.

Experiments in yeast have shown that MRX (MRN) together with Sae2 (CtIP) can resect DSBs to produce a few hundred nucleotides of ssDNA at the break (Symington and Gautier, 2011). To determine whether CtIP mediates DNA end resection at DSBs, we used short hairpin RNAs (sh-CtIP1 and sh-CtIP2) to deplete this protein from activated B cells (Fig. 1 B). CtIP-depleted IgH ${ }^{\mathrm{I}-96 \mathrm{k} /+} 53 \mathrm{BP} 1^{-/-} \mathrm{AID}^{-/-}$ $\mathrm{B}$ lymphocytes expressing I-SceI were isolated by cell sorting, and recombination joins were analyzed by PCR. Loss of CtIP decreased the frequency of joins displaying extensive resection (Fig. $1 \mathrm{C}, 47.8$ to $33.8 \%$; $\mathrm{P}=0.001$ ) and the mean number of resected nucleotides (Fig. 1 C, 124.1 to 63.1 nt; P = 0.006). Moreover, diminished end processing was also observed in 53BP1-proficient B cells (Fig. 1 D, 37.1 to 25.7\%; $\mathrm{P}=0.024)$. We conclude that CtIP is in part responsible for processing intrachromosomal DSBs in the presence or absence of 53BP1.

Exo1 possesses $5^{\prime}$ to $3^{\prime}$ exonuclease and $5^{\prime}$ flap endonuclease activities, which in yeast promote the extension of resected tracts up to $2-5 \mathrm{~kb}$ (Symington and Gautier, 2011). To determine the role of Exo1 in resection, we produced $\mathrm{IgH}^{\mathrm{I}-96 \mathrm{k} /+} 53 \mathrm{BP} 1^{-/-} \mathrm{AID}^{-/-} \mathrm{Exo}^{-/-}$mice by breeding, and then assayed resection of DNA breaks created by I-SceI. Similar to mice expressing a mutant form of Exo1 (Bardwell et al., 2004; Wei et al., 2003), B lymphocyte development was not altered in the absence of Exo1 (unpublished data). Compared with $\mathrm{IgH}^{\mathrm{I}-96 \mathrm{k} /+} 53 \mathrm{BP} 1^{-/-} \mathrm{AID}^{-/-}$Exo1 $1^{+/+}$ controls, junctions with extensive resection were reduced (Fig. 1 E, 51.1 to $27.3 \%$; $\mathrm{P}<0.0001$ ), as was the mean number of resected nucleotides (Fig. 1 E, 96.3 to 53.3 nt; P = 0.020). Lack of Exo1 also resulted in decreased DNAend processing in 53BP1-sufficient B cells (Fig. 1 F, 37.1 to $28.1 \%$; $\mathrm{P}=0.016)$. We conclude that Exo1 resects intrachromosomal DSBs. 

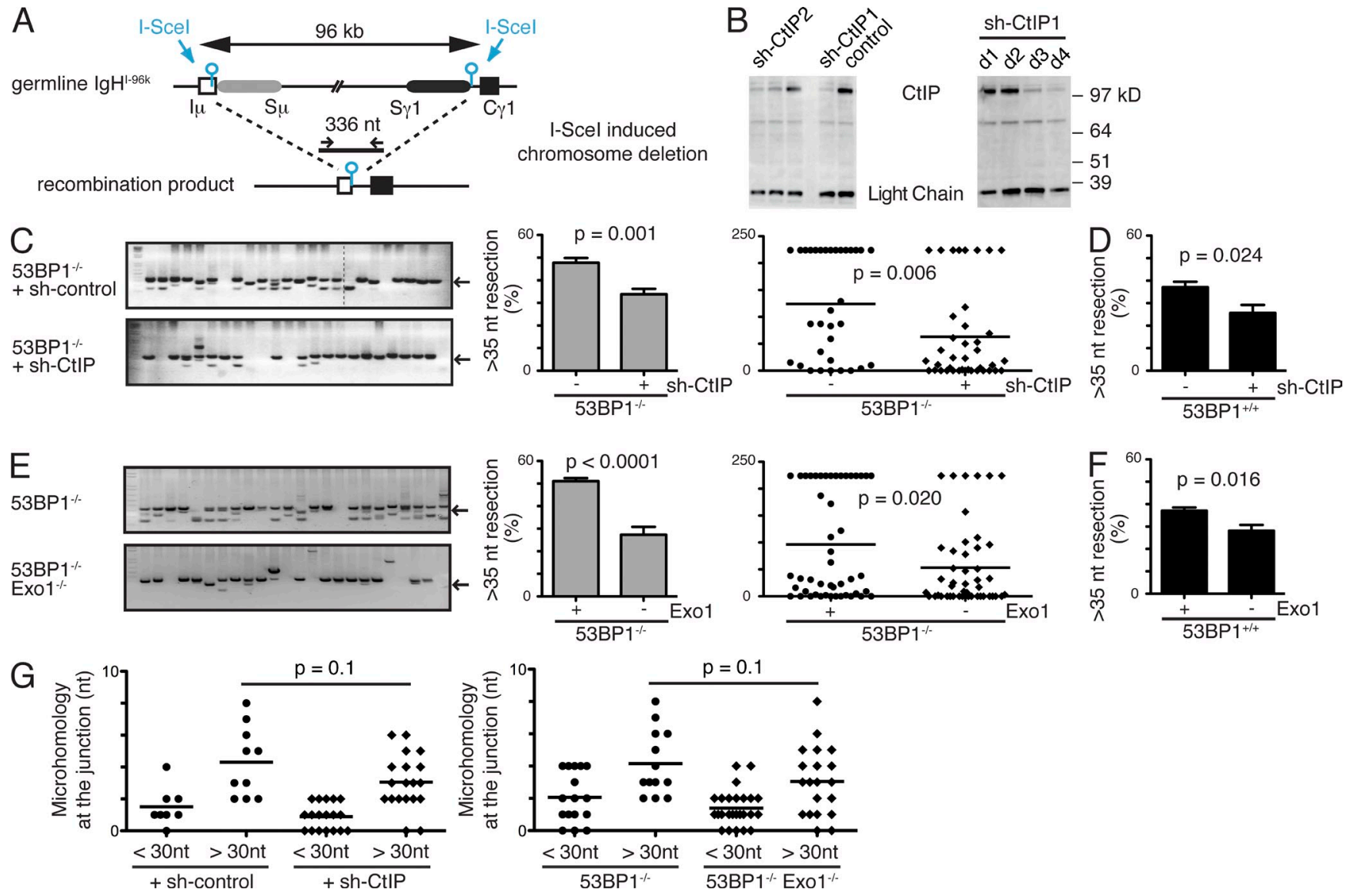

Figure 1. CtIP and Exo1 promote DNA resection during the joining of intrachromosomal I-Scel-induced DSBs. (A) Schematic representation of the IgHI-96k allele before (top) and after (bottom) recombination by I-Scel. Blue circles indicate the I-Scel sites. Black arrows represent the position of the PCR primers for amplifying the recombination products. The perfect (nonresected) join is $336 \mathrm{nt}$. S $\mu$ and $\mathrm{S} \gamma 1$ are Switch $\mu$ and Switch $\gamma 1$ regions, respectively. (B, left) Identification of sh-RNAs against CtIP. Western Blot analysis of protein lysates from activated B cells infected with candidate shRNAs and analyzed after $96 \mathrm{~h}$ in culture. The two best shRNAs were selected for the experiments (sh-CtIP1 and sh-CtIP2). (right) Time course of knock down by sh-CtIP1 ( $d$ = days since beginning of the culture). Two and one experiment, respectively. ( $C$, left) Representative ethidium bromide-stained agarose gels

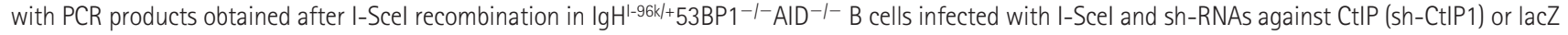
(sh-control), followed by sorting of the double-infected population. Arrows point to the $300 \mathrm{nt}$ size, under which bands are scored as extensively resected. Vertical dotted line indicates merge of two adjacent pictures of the same gel. (middle) Histogram with the frequency of I-Scel-induced recombination products with extensive resection (>35 nt). (right) Resection dot plot, with each dot representing one sequence. On the $Y$ axis is the number of resected

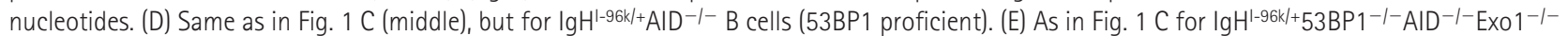

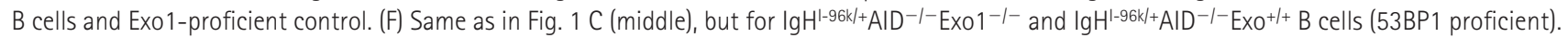

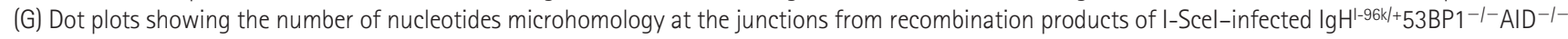
$\mathrm{B}$ cells from the indicated experimental conditions. Sequences were grouped according to the extent of resection (more or less than $30 \mathrm{nt}$ ). Error bars in histograms indicate standard deviations. Horizontal lines in dot plots indicate the means. P-values were calculated using the unpaired two-tailed Student's $t$ test. All graphs represent data from at least two separate PCR reactions for each of two independent experiments.

Chromosome translocation breakpoints are often characterized by the presence of microhomology (Gostissa et al., 2011). To determine if the partial decrease in DNA end resection in the absence of CtIP or Exo1 was accompanied by changes in junctional microhomology, we sequenced recombination products (Figs. 1, C and E) and measured the extent of microhomology. We found that the remaining resected joins are still characterized by extensive junctional microhomology (Fig. $1 \mathrm{G}$ ). This indicates that neither of the two nucleases alone is required for DNA repair by A-NHEJ.

\section{Mre11, Wrn, and BIm}

Mre11, a component of the MRN complex, has been implicated in DNA end resection both in yeast and mammalian cells (Symington and Gautier, 2011). To test the role of Mre11 in resection in B cells, we treated I-SceI-expressing IgH $\mathrm{I}^{\mathrm{I}-96 \mathrm{k} /+} 53 \mathrm{BP}^{-/-} \mathrm{AID}^{-/-}$cultures with the small molecule inhibitor Mirin at the biologically active concentration of $10 \mu \mathrm{M}$ (Dupré et al., 2008; and unpublished data). No measurable effect on resection was observed after Mre11 inhibition (Fig. 2 A). In addition, we found no difference in the microhomology at the junctions (unpublished data). 

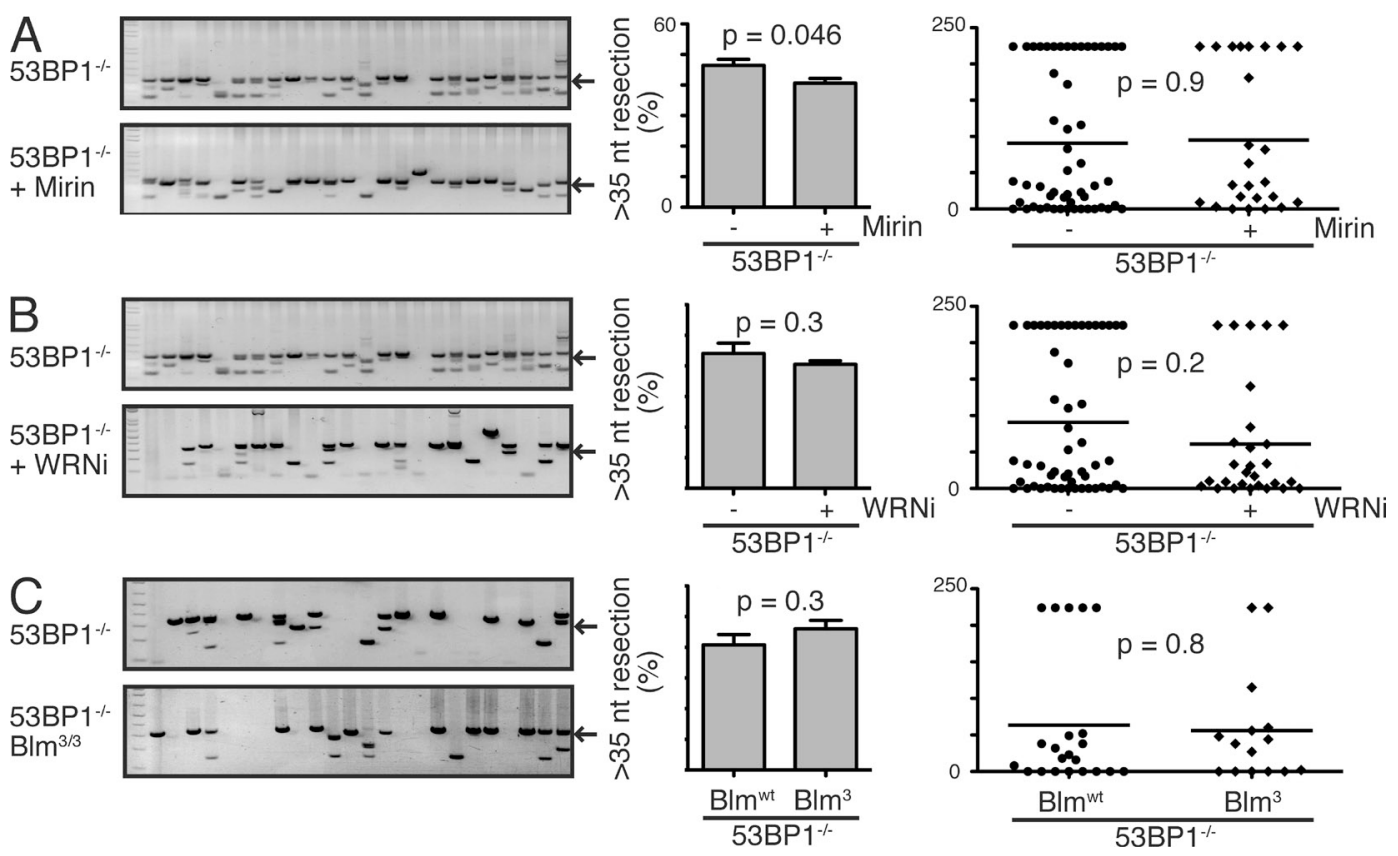

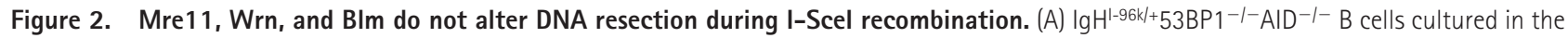
presence or absence of the Mre11 inhibitor (Mirin) as in Fig. 1 C. The frequency of joins with extensive resection was $46.5 \%$ for untreated and $40.6 \%$ for

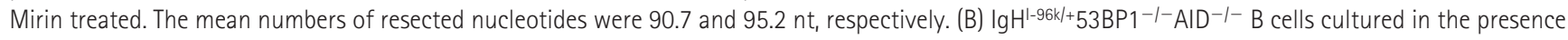
or absence of the Wrn inhibitor (WRNi) as in Fig. 1 C. The frequency of joins with extensive resection was 44.1\% for untreated and $40.5 \%$ for WRNi

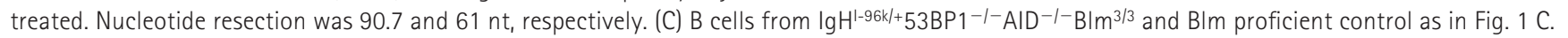
The frequency of joins with extensive resection was $40.8 \%$ for Blm-proficient and $46.1 \%$ for B $\mathrm{Im}^{3}$. Nucleotide resection was 63.4 and $53.3 \mathrm{nt}$, respectively. All graphs represent data from at least two separate PCR reactions for each of two independent experiments.

We conclude that, in contrast to CtIP, inhibition of Mre11 does not alter DNA end resection in 53BP1-deficient B cells.

Sgs1, a RecQ DNA helicase, has been implicated together with Exo1 in the extension of DNA end resection in yeast (Symington and Gautier, 2011). Five RecQ proteins exist in mammals (Wrn, Blm, RecQ1, RecQ4, and RecQ5). Although Blm is viewed as the closest orthologue of Sgs1, Wrn is the only family member that possesses both DNA helicase and $3^{\prime}$ to $5^{\prime}$ exonuclease activities (Brosh and Bohr, 2007). To investigate the role of Wrn in resection, we treated I-SceI-infected $\mathrm{IgH}^{\mathrm{I}-96 \mathrm{k} /+} 53 \mathrm{BP} 1^{-/-}$ $\mathrm{AID}^{-1-}$ lymphocytes with the small molecule inhibitor NSC19630 (WRNi), which specifically blocks Wrn helicase activity (Aggarwal et al., 2011). At the biologically active concentrations of 1.5-2 $\mu \mathrm{M}$ (Aggarwal et al., 2011; and see below), WRNi did not significantly alter resection or junctional microhomology (Fig. $2 \mathrm{~B}$ and not depicted). To determine the role of the Blm helicase, we bred the functionally null $\mathrm{Blm}^{3}$ allele (Luo et al., 2000) to produce $\mathrm{IgH}^{\mathrm{I}-96 \mathrm{k} /+} 53 \mathrm{BP}^{-/-} \mathrm{AID}^{-/-} \mathrm{Blm}^{3 / 3}$ mice. Compared with $\mathrm{IgH}^{\mathrm{I}-96 \mathrm{k} /+} 53 \mathrm{BP}^{-/-} \mathrm{AID}^{-/-} \mathrm{Blm}^{+/+}$controls, neither resection, nor junctional microhomology was significantly altered (Fig. $2 \mathrm{C}$ and not depicted). We conclude that neither Wrn helicase activity nor Blm deficiency significantly alters processing of intrachromosomal DSBs in the absence of 53BP1.

\section{Inhibition of resection promotes $I g$ class switching}

During CSR, B lymphocytes replace Ig $\mu$ by a downstream constant region, such as Ig 1 (Fig. 3 A). 53BP1 and H2AX are essential for this reaction, in part because they protect DNA ends from resection (Petersen et al., 2001; Manis et al., 2004; Ward et al., 2004). Interfering with ATM promotes CSR in the resection-prone 53BP1 $1^{-/-}$and $\mathrm{H}_{2} \mathrm{AX}^{-/-}$backgrounds, and this is associated with inhibition of DSB resection (Bothmer et al., 2010, 2011). To determine whether DNA end resection contributes to this class switch defect, we analyzed CSR in $53 \mathrm{BP}^{-1-}$ and $\mathrm{H} 2 \mathrm{AX}^{-1-} \mathrm{B}$ cells under conditions that impair DNA resection.

First, we tested the role of CtIP by transducing activated $\mathrm{B}$ cells with retroviruses expressing anti-CtIP shRNA. CtIP depletion partially rescued class switching in $53 \mathrm{BP} 1^{-1-}$ and $\mathrm{H}_{2} \mathrm{AX}^{-/-} \mathrm{B}$ cells (Fig. 3 B). The rescue of switching was not associated with significant changes in cell proliferation (unpublished data). Importantly, CtIP knock down did not significantly alter wild-type switching (Fig. 3 C), AID expression, or switch region transcription (Fig. $3 \mathrm{D}$ ). We conclude that DSB resection by CtIP is in part responsible for the switching defect in 53BP1 and H2AX deficiency.

The absence of a CSR defect in CtIP-depleted wild-type cells is in contrast to a report that silencing CtIP reduced AID levels and CSR in the CH12 B cell line (Lee-Theilen et al., 2011). To exclude possible off-target effects of the hairpins 
used for CtIP depletion, we next measured class switching in $\mathrm{B}$ cells that were genetically deficient for CtIP. Because CtIP-null mice are embryonically lethal (Chen et al., 2005), we intercrossed the previously reported CtIP-null allele (CtIP ${ }^{-}$; Chen et al., 2005) to a new CtIP conditional allele $\left(\mathrm{CtIP}^{\mathrm{co}}\right)$, in which exon 2 is flanked by loxP sites (unpublished data; and see Materials and methods). Absence of CtIP was verified by Western Blot (Fig. 4 A). In agreement with
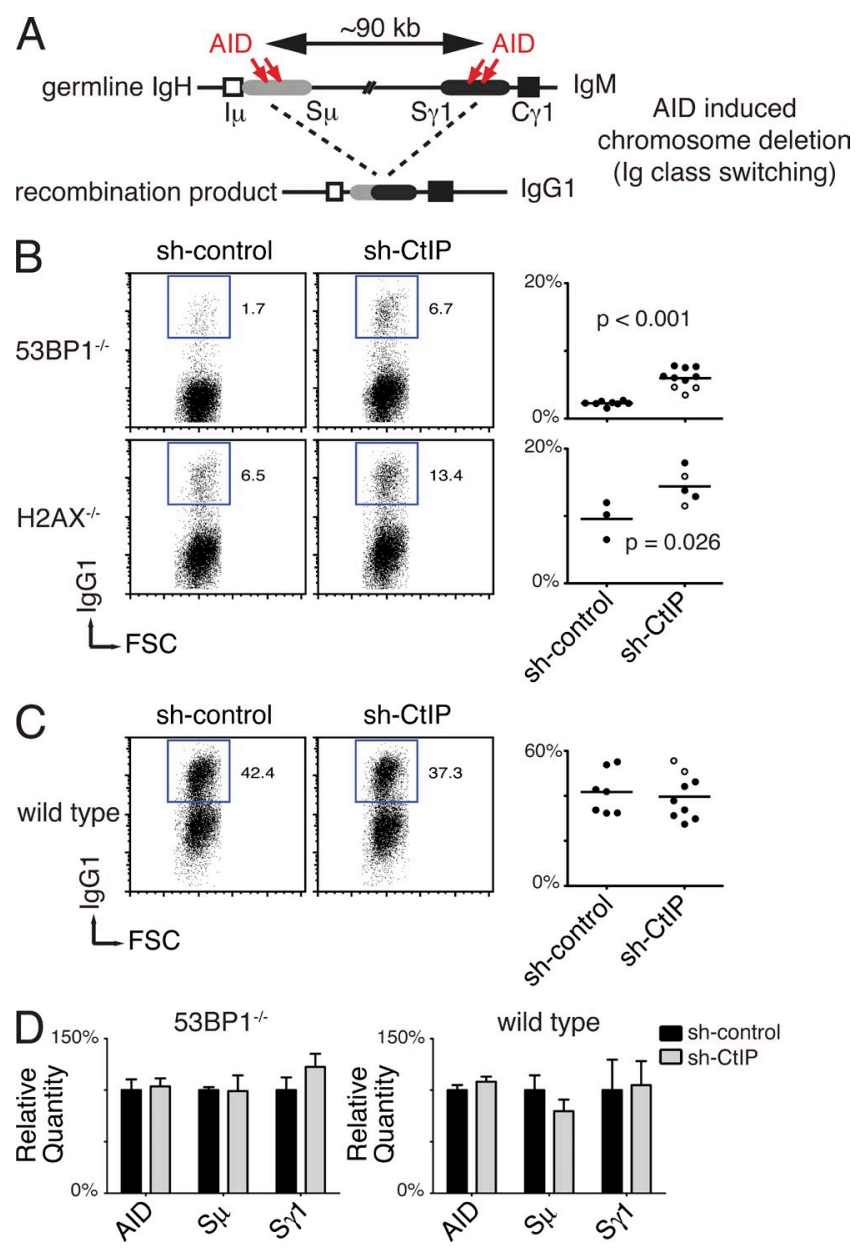

Figure 3. CtIP contributes to the Ig class switch defect of 53BP1-1and $\mathrm{H}_{2} \mathrm{AX} \mathrm{X}^{-1-} \mathrm{B}$ cells. (A) Schematic representation of the $\lg \mathrm{H}$ allele prior (top) and after (bottom) AID-induced recombination, which results in lg class switching from $\lg M$ to $\lg G 1$. ( $B$, left) Representative flow cytometry plots measuring the percentage of CSR to $\lg \mathrm{G} 1$ upon infection of $53 \mathrm{BP} 1^{-1-}$ or $\mathrm{H}_{2} \mathrm{AX}^{-1-} \mathrm{B}$ cells with sh-RNAs against CtIP or lacZ control (gated on the $\mathrm{GFP}^{+}$infected population). Mean CSR values for sh-control and sh-CtIP, respectively: 2.3 and $6.0 \%$ in $53 \mathrm{BP}^{-1-} ; 9.6$ and $14.4 \%$ in $\mathrm{H} 2 \mathrm{AX}{ }^{-1-}$. FSC is forward scatter for cell size. (right) Summary dot plot of class switching results. Filled and empty circles represent results with sh-CtIP1 and shCtIP-2, respectively. Horizontal lines in dot plots indicate the means. P-values were calculated using a paired two-tailed Student's $t$ test. Each dot represents an independent culture. (C) Wild-type cells infected with shRNAs against CtIP, as in B. (D) Q-PCR analysis of AID, and germline switch $\mu$ and switch $\gamma 1$ transcription upon culture of sh-CtIP1-infected $53 \mathrm{BP} 1^{-1-}$ or wild-type cells. Data are expressed as relative quantity of control (black bars). Three independent samples were used. the shRNA results, class switching was not significantly altered by the absence of CtIP (Fig. 4 B). Moreover, in contrast to the reported effect of CtIP depletion on the extent of microhomology at switch junctions of CH12 cells (Lee-Theilen et al., 2011), our analysis of $S \mu-S \gamma 1$ junctions of CD19 ${ }^{\text {cre/+ }} \mathrm{CtIP}^{\mathrm{co} /-} \mathrm{B}$ cells shows a similar pattern to control (Figs. 4, C and D). We conclude that the absence of CtIP does not alter class switching or microhomology at $\mathrm{S} \mu-\mathrm{S} \gamma 1$ junctions in primary B cells.

We next explored the role of helicases. WRNi treatment did not affect wild-type switching (unpublished data). However, CSR was enhanced in both $53 \mathrm{BP}^{-1-}$ and $\mathrm{H} 2 \mathrm{AX}{ }^{-1-}$ $\mathrm{B}$ cells treated with this helicase inhibitor (Fig. $5 \mathrm{~A}$ ). The effect of WRNi was notably more pronounced than ATM inhibitor Ku55933 (ATMi; Bothmer et al., 2010; Fig. 5 A), despite a decrease in AID and switch germline transcripts (Fig. 5 B). Blm deficiency negatively impacts class switching in wildtype B cells (Babbe et al., 2009). To test the role of Blm in a resection-prone background, we generated CD19cre/+$B \operatorname{lm}{ }^{\text {lox } / \text { lox }}$ $53 \mathrm{BP} 1^{-/-}$mice. Switching was increased but only to a small extent by loss of Blm compared with $53 \mathrm{BP} 1^{-/-}$control (Fig. $5 \mathrm{C}$ ), and this was accompanied by higher switch $\mu$ germline transcription (Fig. 5 D). We conclude that 53BP1 and H2AX contribute to Ig class switching in part by preventing the action of Wrn and Blm helicases on DSBs at switch regions.

\section{DISCUSSION}

DSBs predispose to genomic rearrangements, which are common in cancer and are often accompanied by the loss of genetic information (Futreal et al., 2004; Mitelman et al., 2007; Nussenzweig and Nussenzweig, 2010; Robbiani and Nussenzweig, 2012). To investigate the molecular mechanism responsible for the loss of genomic sequence during DNA recombination reactions, we took advantage of a previously established assay to measure the DNA end resection during joining of paired intrachromosomal DSBs in the $I g h$ locus separated by $96 \mathrm{~kb}$ (Bothmer et al., 2010).

CtIP has been implicated in the initial trimming phase of DNA end resection (Symington and Gautier, 2011). Although CtIP deletion is lethal (Chen et al., 2005), knockdown experiments in human cells show that it binds to the MRN complex and promotes accumulation of replication protein A (RPA) at sites of laser-induced DNA damage, suggesting that it produces ssDNA (Sartori et al., 2007). Moreover, although CtIP does not appear to have any direct nuclease activity, enzymatic assays in vitro have demonstrated that it enhances the nuclease activity of the MRN (Sartori et al., 2007). Exo1 has been involved in the extension phase of resection (Symington and Gautier, 2011). In mammalian cells, Exo1 rapidly accumulates at sites of DSBs and is required for proper DNA repair, as its absence leads to chromosome instability and defects in RPA accumulation upon ionizing radiation (Bolderson et al., 2010). In addition, biochemical DNA end resection assays with purified human proteins have shown that Exo1 activity is stimulated by the presence of the MRN, RPA, and BLM (Nimonkar et al., 2011). 

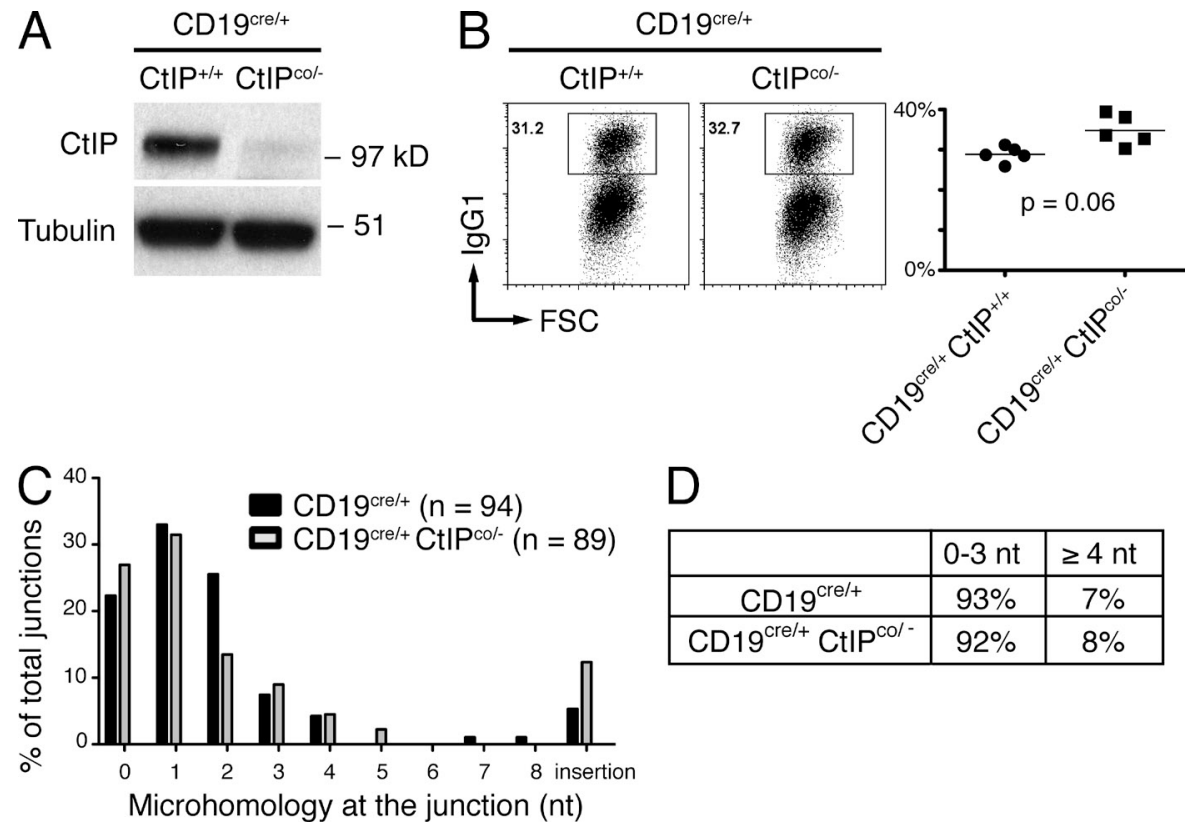

D

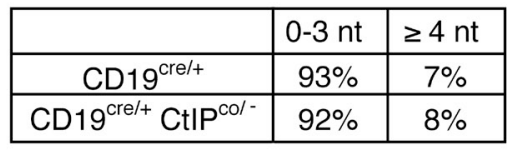

Figure 4. CtIP-deficient B cells have normal class switching and microhomology at switch junctions. (A) Western blot for CtIP on B cells activated in vitro for $2 \mathrm{~d}$. Representative of two experiments. ( $B$, left) Representative flow cytometry plots measuring the percentage of $C S R$ to $\lg G 1$ in B cells of the indicated genotypes. Mean CSR values are 28.9\% for CD $19^{\text {crel }+}+\mathrm{CtIP}^{+/+}$and $34.8 \%$ for CD19crel+CtIPcol- . FSC is forward scatter for cell size. (right) Summary dot plot of class switching results. Horizontal lines in dot plots indicate the means. Each dot represents an independent culture. (C) Nucleotide (nt) microhomology at $\mathrm{S} \mu-\mathrm{S} \gamma 1$ junctions of CD $19^{\text {crel+ }}+$ CtIPcol- and control. Sequences from two independent experiments. (D) Summary of junctions with 0-3 nt microhomology versus extensive microhomology ( $\geq 4 \mathrm{nt}$ ) for the same sequences as in C.
The contribution of CtIP or Exo1 to resection of DSBs that occur during DNA recombination reactions is largely unknown, as are the players responsible for resection in the absence of 53BP1. ATM regulates CtIP and Exo1 by phosphorylation, which controls their accumulation at DSBs (Li et al., 2000; You et al., 2009; Bolderson et al., 2010). Our experiments show that interfering with CtIP or Exo1 significantly reduced DSB resection in 53BP1 $1^{-1-}$ and wild-type $\mathrm{B}$ cells. These results are consistent with and likely account for our finding that inhibiting ATM interferes with DNA end resection (Bothmer et al., 2010). However, neither the knockdown of CtIP nor the knockout of Exo1 abrogates resection entirely, and therefore these two factors are either partially redundant or there are additional, yet to be identified, mechanisms that mediate DNA end resection. Our findings in activated $\mathrm{B}$ cells that CtIP promotes resection are consistent with CtIP promoting resection of DNA ends during $\mathrm{V}(\mathrm{D}) \mathrm{J}$ recombination in H2AX-deficient pre-B cells (Helmink et al., 2011) and supporting DNA deletion during translocation (Zhang and Jasin, 2011).

Microhomologies are frequent at breakpoints of chromosome translocations (Robbiani et al., 2008; Gostissa et al.,
A
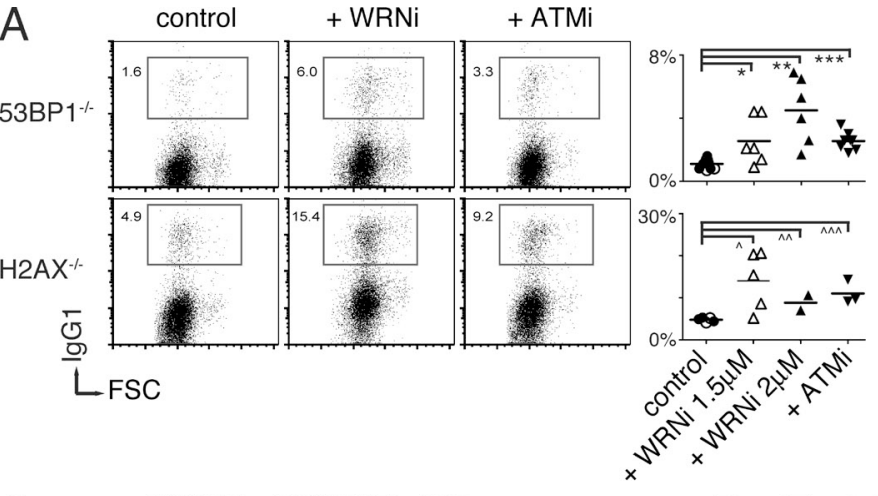

C

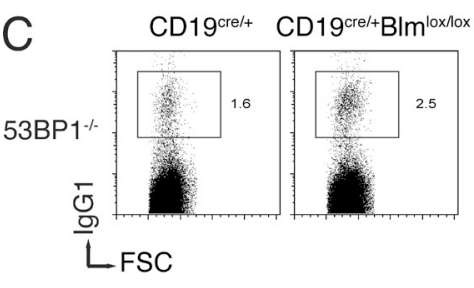

B

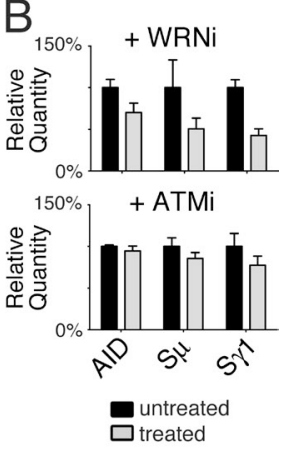

Figure 5. Helicases are in part responsible for the switching defect of 53BP1- and H2AX-deficient B cells. (A) Cells treated with WRNi, ATMi, or controls, as in Fig. 3 B. Filled and empty circles represent results with untreated and DMSO only controls, respectively. Mean CSR values (control, +WRNi $1.5 \mu \mathrm{M}$, + WRNi $2 \mu \mathrm{M}$, and +ATMi, respectively) are as follows: 1.1, 2.6, 4.5, and 2.6\% for 53BP1-1-; 4.8, 14.0, 8.8, and $11.0 \%$ for $\mathrm{H}_{2} \mathrm{AX}^{-1}$ - . P-values for $53 \mathrm{BP}^{-1-}$ are as follows: ${ }^{*}, 0.08 ; *{ }^{*}, 0.02$; ***, 0.0005 ; for $\mathrm{H}_{2} \mathrm{AX}^{-1-}:^{\wedge}, 0.04 i^{\wedge \wedge}, 0.26$; $\stackrel{n}{\wedge}$, 0.05. Each dot represents an independent culture. (B) $53 \mathrm{BP} 1^{-1-}$ cells treated with WRNi or ATMi, as in Fig. 3 D. Three independent samples. (C) CD19crel+Blmloxllox53BP $1^{-1-}$ and control cells (filled triangles are 53BP1-1-, empty triangles are $\mathrm{CD} 19^{\text {crel }}+53 \mathrm{BP}^{-1-}$ ), as in Fig. 3 B. Mean CSR values are 1.8\% in control

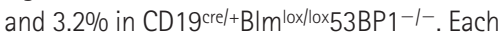
dot represents an independent culture. (D) As

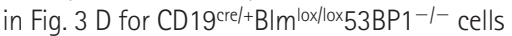
and control. Six independent samples. 
2011). Although classical NHEJ (C-NHEJ) can produce joins with microhomology, these are favored by the A-NHEJ pathway, which joins DSBs when the core C-NHEJ factors (Ku70, Ku80, XRCC4, or Lig4) are absent (Boboila et al., 2010; Gostissa et al., 2011). Thus, the A-NHEJ pathway is particularly active under conditions when DNA ends are poorly protected, such as loss of 53BP1 (Bothmer et al., 2010). Loss of CtIP or Exo1 in 53BP1-deficient cells results in a partial decrease in DNA end resection, but the remaining resected joins still show extensive junctional microhomology. Thus, neither factor alone is essential for DNA repair by A-NHEJ.

Together with CtIP, Mre11 is also involved in the initial trimming of broken DNA ends (Symington and Gautier, 2011). Although chemical inhibition of Mre11 with Mirin did not decrease resection, this treatment also inhibits ATM activation (Dupré et al., 2008), and ATM activity is needed for resection (Bothmer et al., 2010).Thus, it is possible that Mirin also causes defects in joining that interfere with the formation of joins being scored in the assay.

CSR in lymphocytes is profoundly impaired by the absence of 53BP1 or H2AX (Petersen et al., 2001; Manis et al., 2004; Ward et al., 2004; Franco et al., 2006). We have proposed that 53BP1 and H2AX protect broken DNA ends and inhibit resection-associated A-NHEJ while promoting C-NHEJ repair. Because A-NHEJ favors microhomologydriven intra-switch recombination within the repetitive switch regions, inhibiting resection and A-NHEJ would support successful inter-switch recombination (Bothmer et al., 2010, 2011). In agreement with this idea, loss of CtIP in 53BP1deficient cells results in a partial rescue of CSR, and has no significant effect on primary wild-type B cells. Our results are consistent with the observation that CtIP is responsible for resection during $\mathrm{V}(\mathrm{D}) \mathrm{J}$ recombination (Helmink et al., 2011), and contrasts a report that silencing CtIP reduced AID levels and CSR in the CH12 B cell line (Lee-Theilen et al., 2011).

The RecQ family of DNA helicases plays an important role in maintaining genomic stability, and some members have been implicated in the processing of broken DNA ends (Brosh and Bohr, 2007; Gravel et al., 2008; Mimitou and Symington, 2008; Zhu et al., 2008; Nimonkar et al., 2011; Symington and Gautier, 2011). The increase in CSR upon interference with Wrn or Blm helicases contrasts with their lack of effect on resection during recombination between intrachromosomal I-SceI sites. We speculate that the difference in the two assays might arise if Wrn and Blm are not engaged in the repair of paired intrachromosomal I-SceI breaks, but participate in the repair of AID-mediated DNA lesions that occur within the repetitive, G-rich and highly transcribed switch regions (Stavnezer et al., 2008). Genetic experiments will be necessary to clarify the role of Wrn during DNA processing and class switching.

In summary, CSR in lymphocytes is profoundly impaired by the absence of 53BP1 or H2AX and this is associated with increased resection, which favors microhomology- or homologydriven abortive intra-switch recombination within the repetitive switch regions (Petersen et al., 2001; Manis et al., 2004; Ward et al., 2004; Bothmer et al., 2010, 2011). Our experiments reveal that CtIP and Exo1 mediate resection and that preventing nucleolytic processing of broken DNA ends promotes Ig class switching.

\section{MATERIALS AND METHODS}

Mice. IgH ${ }^{\mathrm{I}-96 \mathrm{k}}$ (Bothmer et al., 2010), $\mathrm{AID}^{-/-}$(Muramatsu et al., 2000), $53 \mathrm{BP}^{-1-}$ (Ward et al., 2004), $\mathrm{Blm}^{3}$ (Blm $^{\mathrm{tm} 3 \mathrm{Brd}}$, NCI mouse repository; Luo et al., 2000), Blm ${ }^{\text {lox } / \text { lox }}$ (Blm ${ }^{\text {tm } 4 \text { Ches; }}$ P. Leder, Harvard University, Boston, MA Chester et al., 2006), CD19 ${ }^{\text {Cre }}$ (Rickert et al., 1997), $\mathrm{CtIP}^{+/-}$(Chen et al., 2005), and $\mathrm{H}_{2} \mathrm{AX}^{-/-}$(Petersen et al., 2001; Celeste et al., 2002) mice were previously described. Exo1 ${ }^{-/-}$mice were generated by homologous recombination in WW6 embryonic stem cells. In the conditional CtIP allele $\left(\mathrm{CtIP}^{\mathrm{co}}\right)$, exon 2 (encoding the N-terminal 36 aa, including the initiator methionine) is flanked by a pair of loxP recombination signals. It was generated using a conditional CtIP targeting vector, which consisted of a 7.7-kb genomic fragment containing exons 1 and 2. One loxP site was inserted into a unique Nhe site in intron 1, while a second loxP site together with an FRT-flanked PGK-neo cassette (with a transcriptional orientation opposite to that of CtIP) was cloned into a unique EcoRV site in intron 2. A HSV-thymidine kinase (HSV-TK) gene cassette was included in the construct as a negative selection marker against random integration. Gene targeting in 129Sv ES cells and blastocyst injections were performed after standard techniques. The FRT-flanked PGK-neo cassette was removed by mating heterozygous $\mathrm{CtIP}^{\text {coneo/+ }}$ mice with FLPeR mice (The Jackson Laboratory). Unless otherwise specified, mice were homozygous for the indicated alleles. All experiments were in accordance with protocols approved by the Rockefeller University Institutional Animal Care and Use Committee.

$B$ cell culture and retroviral infection. For I-SceI recombination and CSR assays, $\mathrm{CD} 43^{-}$resting $\mathrm{B}$ cells were isolated from spleens, stimulated with LPS and interleukin 4 (IL-4), and infected as previously described (Bothmer et al., 2011). The pMX-IRES-GFP based retrovirus encoding for I-SceI was previously described (Robbiani et al., 2008). For double-infection experiments, I-SceI was cloned into pMX-IRES-mCherry. The short hairpins were as follows: sh-control (against lacZ), 5' -TGCTGTTGACAGTGAGCGAGGCCTGTATGTGGTGGATGAATAGTGAAGCCACAGATGTATTCATCCACCACATACAGGCCGTGCCTACTGCCTCGGA-3'; sh-CtIP1, 5'-TGCTGTTGACAGTGAGCGAGCTCTCTATGTACAAATGAATTAGTGAAGCCACAGATGTAATTCATTTGTACATAGAGAGCGTGCCTACTGCCTCGGA-3' ; and sh-CtIP2, 5'-TGCTGTTGACAGTGAGCGCGTAAATTCTCTCCAGACCAAATAGTGAAGCCACAGATGTATTTGGTCTGGAGAGAATTTACTTGCCTACTGCCTCGGA-3'. Sh-RNAs were cloned into a pMX-IRES-GFP backbone upon amplification with the following primers: fwd, 5' -CAGAAGGCTCGAGAAGGTATATTGCTGTTGACAGTGAGCG-3' ; rev, 5' -CTAAAGTAGCCCCTTGAATTCCGAGGCAGTAGGCA-3' . Cultures were analyzed at $96 \mathrm{~h}$.

PCR assay for measuring resection. The PCR assay for measuring resection at recombination joins was performed as detailed previously (Bothmer et al., 2010). In brief, B cells were infected in vitro and analyzed after $4 \mathrm{~d}$. Nested PCR reactions with primers flanking the I-SceI recognition sites (see Fig. 1 A) were performed on genomic DNA that was diluted for detection of single recombination events. PCR products were run on agarose gels and scored by visual inspection for resection of $>35 \mathrm{nt}$ and extracted for direct sequencing.

Small molecule inhibitors. Mirin (TOCRIS Bioscience; Dupré et al., 2008) was used at $10 \mu \mathrm{M}$; ATMi (Ku55933; TOCRIS Bioscience) was used at $2.5 \mu \mathrm{M}$; and WRNi (NSC19630, NCI Diversity Set; Aggarwal et al., 2011) was used at $1.5 \mu \mathrm{M}$ or $2 \mu \mathrm{M}$, as indicated. 
Flow cytometry and cell sorting. B cell cultures co-infected with I-SceI $\left(\right.$ mCherry $\left.^{+}\right)$and sh-RNA $\left(\mathrm{GFP}^{+}\right)$were sorted for double-positivity on a FACSAria (BD). For Ig class switch assays, cell suspensions were stained with fluorochrome-conjugated anti-IgG1 antibodies (BD). For cell division analysis, cells were labeled at $37^{\circ} \mathrm{C}$ for $10 \mathrm{~min}$ in $2.5 \mu \mathrm{M}$ CFSE. Samples were acquired on a FACSCalibur (BD) and analyzed with FlowJo (Tree Star).

Western Blot. In Fig. 1 B CtIP was detected in whole-cell extracts with the antibody A300-488A (Bethyl Laboratories), followed by secondary antilight chain. In Fig. 4 A, antibody 14-1 was used (Yu and Baer, 2000).

Q-PCR for AID and germline transcripts. RNA from stimulated B cells (96 h) was extracted from TRIzol (Invitrogen), followed by cDNA preparation with Superscript II Reverse transcription (Invitrogen) according to the manufacturer's protocol. Q-PCR was performed using the Brilliant III SYBR Green Q-PCR Master Mix (Agilent). Reactions were performed in triplicates for each of at least three mice of each genotype, and analyzed using MX3005P Q-PCR software (Stratagene). Values were normalized to GAPDH. The following primers were used: GAPDH-F, $5^{\prime}$-TGAAGCAGGCATCTGAGGG-3'; GAPDH-R, 5' -CGAAGGTGGAAGAGTGGGAG-3'; AID-F, 5'-GAAAGTCACGCTGGAGACCG-3'; AID-R, 5'-TCTCATGCCGTCCCTTGG-3'; $\mu$ GLT-F, 5' -TAGTAAGCGAGGCTCTAAAAAGCAT-3'; $\mu$ GLT-R, 5'-AGAACAGTCCAGTGTAGGCAGTAGA-3'; $\gamma 1$ GLT-F, 5'-GGCCCTTCCAGATCTTTGAG-3'; r1GLT-R, 5'-GGATCCAGAGTTCCAGGTCACT-3'.

Analysis of microhomology at switch junctions. DNA was harvested from cultured B cells and amplified using nested reactions. First reaction: 5'-AATGGATACCTCAGTGGTTTTTAATGGTGGGTT-3 and 5-CAATTAGCTCCTGCTCTTCTGTGG-3'. Nested reaction: 5'-GACCCAGGCTAAGAAGGCAATCC-3 and 5-GACTGGGTTCCCACACTCTTACCTGCC- $3^{\prime}$. After cloning in TOPO vector and sequencing, microhomology was determined by manual alignment.

We thank members of the Nussenzweig laboratory for discussions; David Bosque, Tom Eisenreich, and Kai-Hui Yao for technical assistance; and Klara Velinzon and Yelena Shatalina for FACS sorting. We are grateful to Phil Leder for the BIm ${ }^{\text {loxllox }}$ mice.

This work was supported in part by National Institutes of Health $(\mathrm{NIH})$ grant Al037526 to M.C. Nussenzweig and CA93484 to W. Edelmann, and by the NIH Intramural Research Program of National Insitute of Arthritis and Musculoskeletal and Skin Diseases (R. Casellas) and National Institute on Aging (R.M. Brosh). A. Bothmer was a predoctoral fellow of the Cancer Research Institute, M.F. Muellenbeck was a Boehringer Ingelheim Funds fellow, and M.C. Nussenzweig is a Howard Hughes Medical Institute Investigator.

The authors have no conflicting financial interests.

Submitted: 3 September 2012

Accepted: 29 November 2012

\section{REFERENCES}

Aggarwal, M., J.A. Sommers, R.H. Shoemaker, and R.M. Brosh Jr. 2011. Inhibition of helicase activity by a small molecule impairs Werner syndrome helicase (WRN) function in the cellular response to DNA damage or replication stress. Proc. Natl. Acad. Sci. USA. 108:1525-1530. http://dx.doi.org/10.1073/pnas.1006423108

Babbe, H., J. McMenamin, E. Hobeika, J. Wang, S.J. Rodig, M. Reth, and P. Leder. 2009. Genomic instability resulting from Blm deficiency compromises development, maintenance, and function of the $\mathrm{B}$ cell lineage. J. Immunol. 182:347-360.

Bardwell, P.D., C.J. Woo, K. Wei, Z. Li, A. Martin, S.Z. Sack, T. Parris, W. Edelmann, and M.D. Scharff. 2004. Altered somatic hypermutation and reduced class-switch recombination in exonuclease 1-mutant mice. Nat. Immunol. 5:224-229. http://dx.doi.org/10.1038/ni1031

Bensimon, A., A. Schmidt, Y. Ziv, R. Elkon, S.Y. Wang, D.J. Chen, R. Aebersold, and Y. Shiloh. 2010. ATM-dependent and -independent dynamics of the nuclear phosphoproteome after DNA damage. Sci. Signal. 3:rs3. http://dx.doi.org/10.1126/scisignal.2001034

Boboila, C., M. Jankovic, C.T. Yan, J.H. Wang, D.R. Wesemann, T. Zhang, A. Fazeli, L. Feldman, A. Nussenzweig, M. Nussenzweig, and F.W. Alt. 2010. Alternative end-joining catalyzes robust IgH locus deletions and translocations in the combined absence of ligase 4 and Ku70. Proc. Natl. Acad. Sci. USA. 107:3034-3039. http://dx.doi.org/10.1073/pnas .0915067107

Bolderson, E., N. Tomimatsu, D.J. Richard, D. Boucher, R. Kumar,T.K. Pandita, S. Burma, and K.K. Khanna. 2010. Phosphorylation of Exo1 modulates homologous recombination repair of DNA double-strand breaks. Nucleic Acids Res. 38:1821-1831. http://dx.doi.org/10.1093/nar/gkp1164

Bothmer, A., D.F. Robbiani, N. Feldhahn, A. Gazumyan, A. Nussenzweig, and M.C. Nussenzweig. 2010. 53BP1 regulates DNA resection and the choice between classical and alternative end joining during class switch recombination. J. Exp. Med. 207:855-865. http://dx.doi.org/10.1084/ jem.20100244

Bothmer, A., D.F. Robbiani, M. Di Virgilio, S.F. Bunting, I.A. Klein, N. Feldhahn, J. Barlow, H.T. Chen, D. Bosque, E. Callen, et al. 2011. Regulation of DNA end joining, resection, and immunoglobulin class switch recombination by 53BP1. Mol. Cell. 42:319-329. http://dx.doi .org/10.1016/j.molcel.2011.03.019

Brosh, R.M. Jr., and V.A. Bohr. 2007. Human premature aging, DNA repair and RecQ helicases. Nucleic Acids Res. 35:7527-7544. http:// dx.doi.org/10.1093/nar/gkm1008

Bunting, S.F., E. Callén, N. Wong, H.T. Chen, F. Polato, A. Gunn, A. Bothmer, N. Feldhahn, O. Fernandez-Capetillo, L. Cao, et al. 2010. 53BP1 inhibits homologous recombination in Brca1-deficient cells by blocking resection of DNA breaks. Cell. 141:243-254. http://dx.doi .org/10.1016/j.cell.2010.03.012

Celeste, A., S. Petersen, P.J. Romanienko, O. Fernandez-Capetillo, H.T Chen, O.A. Sedelnikova, B. Reina-San-Martin,V. Coppola, E. Meffre, M.J. Difilippantonio, et al. 2002. Genomic instability in mice lacking histone H2AX. Science. 296:922-927. http://dx.doi.org/10.1126/science .1069398

Chen, P.L., F. Liu, S. Cai, X. Lin, A. Li, Y. Chen, B. Gu, E.Y. Lee, and W.H. Lee. 2005. Inactivation of CtIP leads to early embryonic lethality mediated by G1 restraint and to tumorigenesis by haploid insufficiency. Mol. Cell. Biol. 25:3535-3542. http://dx.doi.org/10.1128/ MCB.25.9.3535-3542.2005

Chester, N., H. Babbe, J. Pinkas, C. Manning, and P. Leder. 2006. Mutation of the murine Bloom's syndrome gene produces global genome destabilization. Mol. Cell. Biol. 26:6713-6726. http://dx.doi.org/10.1128/ MCB.00296-06

Chiarle, R., Y. Zhang, R.L. Frock, S.M. Lewis, B. Molinie, Y.J. Ho, D.R. Myers, V.W. Choi, M. Compagno, D.J. Malkin, et al. 2011. Genomewide translocation sequencing reveals mechanisms of chromosome breaks and rearrangements in B cells. Cell. 147:107-119. http://dx.doi.org/ 10.1016/j.cell.2011.07.049

Dupré, A., L. Boyer-Chatenet, R.M. Sattler, A.P. Modi, J.H. Lee, M.L. Nicolette, L. Kopelovich, M. Jasin, R. Baer, T.T. Paull, and J. Gautier. 2008. A forward chemical genetic screen reveals an inhibitor of the Mre11-Rad50-Nbs1 complex. Nat. Chem. Biol. 4:119-125. http://dx .doi.org/10.1038/nchembio.63

Franco, S., F.W. Alt, and J.P. Manis. 2006. Pathways that suppress programmed DNA breaks from progressing to chromosomal breaks and translocations. DNA Repair (Amst.). 5:1030-1041. http://dx.doi.org/ 10.1016/j.dnarep.2006.05.024

Futreal, P.A., L. Coin, M. Marshall, T. Down, T. Hubbard, R. Wooster, N. Rahman, and M.R. Stratton. 2004. A census of human cancer genes. Nat. Rev. Cancer. 4:177-183. http://dx.doi.org/10.1038/nrc1299

Gostissa, M., F.W.Alt, and R. Chiarle. 2011. Mechanisms that promote and suppress chromosomal translocations in lymphocytes. Annu. Rev. Immunol. 29 319-350. http://dx.doi.org/10.1146/annurev-immunol-031210-101329

Gravel, S., J.R. Chapman, C. Magill, and S.P. Jackson. 2008. DNA helicases Sgs1 and BLM promote DNA double-strand break resection. Genes Dev. 22:2767-2772. http://dx.doi.org/10.1101/gad.503108

Hakim, O., W. Resch, A. Yamane, I. Klein, K.R. Kieffer-Kwon, M. Jankovic, T. Oliveira, A. Bothmer, T.C. Voss, C. Ansarah-Sobrinho, et al. 2012. 
DNA damage defines sites of recurrent chromosomal translocations in B lymphocytes. Nature. 484:69-74.

Helmink, B.A., A.T. Tubbs, Y. Dorsett, J.J. Bednarski, L.M. Walker, Z. Feng, G.G. Sharma, P.J. McKinnon, J. Zhang, C.H. Bassing, and B.P. Sleckman. 2011. H2AX prevents CtIP-mediated DNA end resection and aberrant repair in G1-phase lymphocytes. Nature. 469:245-249.http://dx.doi.org/ 10.1038/nature09585

Klein, I.A., W. Resch, M. Jankovic, T. Oliveira, A. Yamane, H. Nakahashi, M. Di Virgilio, A. Bothmer, A. Nussenzweig, D.F. Robbiani, et al. 2011. Translocation-capture sequencing reveals the extent and nature of chromosomal rearrangements in B lymphocytes. Cell. 147:95-106. http:// dx.doi.org/10.1016/j.cell.2011.07.048

Lee-Theilen, M., A.J. Matthews, D. Kelly, S. Zheng, and J. Chaudhuri. 2011. CtIP promotes microhomology-mediated alternative end joining during class-switch recombination. Nat. Struct. Mol. Biol. 18:75-79. http://dx.doi.org/10.1038/nsmb.1942

Li, S., N.S. Ting, L. Zheng, P.L. Chen, Y. Ziv, Y. Shiloh, E.Y. Lee, and W.H. Lee. 2000. Functional link of BRCA1 and ataxia telangiectasia gene product in DNA damage response. Nature. 406:210-215. http:// dx.doi.org/10.1038/35018134

Luo, G., I.M. Santoro, L.D. McDaniel, I. Nishijima, M. Mills, H.Youssoufian, H. Vogel, R.A. Schultz, and A. Bradley. 2000. Cancer predisposition caused by elevated mitotic recombination in Bloom mice. Nat. Genet. 26:424-429. http://dx.doi.org/10.1038/82548

Manis, J.P., J.C. Morales, Z. Xia, J.L. Kutok, F.W. Alt, and P.B. Carpenter. 2004. 53BP1 links DNA damage-response pathways to immunoglobulin heavy chain class-switch recombination. Nat. Immunol. 5:481-487. http://dx.doi.org/10.1038/ni1067

Matsuoka, S., B.A. Ballif, A. Smogorzewska, E.R. McDonald III, K.E. Hurov, J. Luo, C.E. Bakalarski, Z. Zhao, N. Solimini, Y. Lerenthal, et al. 2007. ATM and ATR substrate analysis reveals extensive protein networks responsive to DNA damage. Science. 316:1160-1166. http://dx.doi.org/10 $.1126 /$ science. 1140321

Mimitou, E.P., and L.S. Symington. 2008. Sae2, Exo1 and Sgs1 collaborate in DNA double-strand break processing. Nature. 455:770-774. http:// dx.doi.org/10.1038/nature 07312

Mitelman, F., B. Johansson, and F. Mertens. 2007. The impact of translocations and gene fusions on cancer causation. Nat. Rev. Cancer. 7:233-245. http://dx.doi.org/10.1038/nrc2091

Muramatsu, M., K. Kinoshita, S. Fagarasan, S.Yamada,Y. Shinkai, and T. Honjo 2000. Class switch recombination and hypermutation require activationinduced cytidine deaminase (AID), a potential RNA editing enzyme. Cell. 102:553-563. http://dx.doi.org/10.1016/S0092-8674(00)00078-7

Neuberger, M.S., J.M. Di Noia, R.C. Beale, G.T. Williams, Z. Yang, and C. Rada. 2005. Somatic hypermutation at A.T pairs: polymerase error versus dUTP incorporation. Nat. Rev. Immunol. 5:171-178. http://dx .doi.org $/ 10.1038 /$ nri1553

Nimonkar, A.V., J. Genschel, E. Kinoshita, P. Polaczek, J.L. Campbell, C. Wyman, P. Modrich, and S.C. Kowalczykowski. 2011. BLM-DNA2RPA-MRN and EXO1-BLM-RPA-MRN constitute two DNA end resection machineries for human DNA break repair. Genes Dev. 25: 350-362. http://dx.doi.org/10.1101/gad.2003811

Noon, A.T., and A.A. Goodarzi. 2011. 53BP1-mediated DNA double strand break repair: insert bad pun here. DNA Repair (Amst.). 10:1071-1076. http://dx.doi.org/10.1016/j.dnarep.2011.07.012

Nussenzweig, A., and M.C. Nussenzweig. 2010. Origin of chromosomal translocations in lymphoid cancer. Cell. 141:27-38. http://dx.doi.org/ 10.1016/j.cell.2010.03.016
O'Driscoll, M., and P.A. Jeggo. 2006. The role of double-strand break repair - insights from human genetics. Nat. Rev. Genet. 7:45-54. http:// dx.doi.org $/ 10.1038 / \operatorname{nrg} 1746$

Petersen, S., R. Casellas, B. Reina-San-Martin, H.T. Chen, M.J. Difilippantonio, P.C. Wilson, L. Hanitsch, A. Celeste, M. Muramatsu, D.R. Pilch, et al. 2001. AID is required to initiate Nbs1/gamma-H2AX focus formation and mutations at sites of class switching. Nature. 414:660-665. http:// dx.doi.org/10.1038/414660a

Reina-San-Martin, B., H.T. Chen, A. Nussenzweig, and M.C. Nussenzweig. 2004. ATM is required for efficient recombination between immunoglobulin switch regions. J. Exp. Med. 200:1103-1110. http://dx.doi.org/ 10.1084/jem.20041162

Rickert, R.C., J. Roes, and K. Rajewsky. 1997. B lymphocyte-specific, Cre-mediated mutagenesis in mice. Nucleic Acids Res. 25:1317-1318. http://dx.doi.org/10.1093/nar/25.6.1317

Robbiani, D.F., and M.C. Nussenzweig. 2012. Chromosome Translocation, B Cell Lymphoma, and Activation-induced Cytidine Deaminase. Annu. Rev. Pathol.

Robbiani, D.F., A. Bothmer, E. Callen, B. Reina-San-Martin, Y. Dorsett, S. Difilippantonio, D.J. Bolland, H.T. Chen, A.E. Corcoran, A. Nussenzweig, and M.C. Nussenzweig. 2008. AID is required for the chromosomal breaks in c-myc that lead to $\mathrm{c}-\mathrm{myc} / \mathrm{IgH}$ translocations. Cell. 135:1028-1038. http://dx.doi.org/10.1016/j.cell.2008.09.062

Sartori, A.A., C. Lukas, J. Coates, M. Mistrik, S. Fu, J. Bartek, R. Baer, J. Lukas, and S.P. Jackson. 2007. Human CtIP promotes DNA end resection. Nature. 450:509-514. http://dx.doi.org/10.1038/nature06337

Stavnezer, J., J.E. Guikema, and C.E. Schrader. 2008. Mechanism and regulation of class switch recombination. Annu. Rev. Immunol. 26:261-292. http://dx.doi.org/10.1146/annurev.immunol.26.021607.090248

Symington, L.S., and J. Gautier. 2011. Double-strand break end resection and repair pathway choice. Annu. Rev. Genet. 45:247-271. http:// dx.doi.org/10.1146/annurev-genet-110410-132435

Ward, I.M., B. Reina-San-Martin, A. Olaru, K. Minn, K. Tamada, J.S. Lau, M. Cascalho, L. Chen, A. Nussenzweig, F. Livak, et al. 2004. 53BP1 is required for class switch recombination. J. Cell Biol. 165:459-464. http://dx.doi.org/10.1083/jcb.200403021

Wei, K., A.B. Clark, E. Wong, M.F. Kane, D.J. Mazur, T. Parris, N.K. Kolas, R. Russell, H. Hou Jr., B. Kneitz, et al. 2003. Inactivation of Exonuclease 1 in mice results in DNA mismatch repair defects, increased cancer susceptibility, and male and female sterility. Genes Dev. 17:603-614. http://dx.doi.org/10.1101/gad.1060603

You, Z., L.Z. Shi, Q. Zhu, P. Wu, Y.W. Zhang, A. Basilio, N. Tonnu, I.M. Verma, M.W. Berns, and T. Hunter. 2009. CtIP links DNA doublestrand break sensing to resection. Mol. Cell. 36:954-969. http://dx.doi .org/10.1016/j.molcel.2009.12.002

Yu, X., and R. Baer. 2000. Nuclear localization and cell cycle-specific expression of CtIP, a protein that associates with the BRCA1 tumor suppressor. J. Biol. Chem. 275:18541-18549. http://dx.doi.org/10.1074/jbc .M909494199

Zhang, Y., and M. Jasin. 2011. An essential role for CtIP in chromosomal translocation formation through an alternative end-joining pathway. Nat. Struct. Mol. Biol. 18:80-84. http://dx.doi.org/10.1038/nsmb.1940

Zhang,Y., R.P. McCord, Y.J. Ho, B.R. Lajoie, D.G. Hildebrand, A.C. Simon, M.S. Becker, F.W. Alt, and J. Dekker. 2012. Spatial organization of the mouse genome and its role in recurrent chromosomal translocations. Cell. 148:908-921. http://dx.doi.org/10.1016/j.cell.2012.02.002

Zhu, Z., W.H. Chung, E.Y. Shim, S.E. Lee, and G. Ira. 2008. Sgs1 helicase and two nucleases Dna2 and Exo1 resect DNA double-strand break ends. Cell. 134:981-994. http://dx.doi.org/10.1016/j.cell.2008.08.037 